\title{
A Pilot Survey on Knowledge,Attitude and Practice Towards the Islamisation of Knowledge As Perceived by the Staff of Kulliyyah of Allied Health Sciences, International Islamic University Malaysia
}

Intan Azura SHAHDAN ${ }^{1}$, Sarah RAHMAT ${ }^{2}$, Ilyanoon ZAHARI ${ }^{3}$, Sharifah Nurul Natasha Syed Abdul Rahman ${ }^{2}$, Mohd. Affendi Mohd. Shafri ${ }^{1}$.

${ }^{1}$ Kulliyyah of Allied Health Sciences, International Islamic University Malaysia,Kuantan ${ }^{2}$ Audiology and Speech-Language Pathology Dept, Kulliyyah of Allied Health Sciences, International Islamic University Malaysia,Kuantan Pahang, Malaysia, ${ }^{3}$ Optometry and Visual Sciences Dept, Kulliyyah of Allied Health Sciences, International Islamic University Malaysia, Kuantan, Pahang, Malaysia.

ABSTRACT

This preliminary study investigated the: (i) level of knowledge, attitude and practice (KAP) among members of Kulliyyah of Allied Health Sciences (KAHS), International Islamic University Malaysia (IIUM) regarding Islamisation of knowledge (IOK); (ii) correlation of KAP and IOK with the duration of service and level of exposure to IOK-related activities; (iii) comparison of KAP between departments in KAHS towards the understanding of IOK, and (iv) level of KAP in IOK between KAHS academics and non-academic staff. Since studies on the integration of religious worldview in health sciences faculties are scarce, this study will be investigating the effectiveness of IOK programmes at the faculty level. A total of 74 staff participated in the study. The response rate was $65.5 \%$ out of 113 distributed questionnaires. All respondents have average knowledge $(50 \pm 28 \%)$ in IOK and showed positive attitude $(78 \pm 32.5 \%)$ towards IOK. The knowledge of Islamisation in KAHS correlates positively with the duration of service $(p<0.05)$ and the level of exposure to IOK-related activities $(p<0.05)$. However, answers given to some questions indicated that the staff perceptions and knowledge of IOK are ambiguous and may suggest a misunderstanding of the Islamisation term. Furthermore, an average score was found among the academic respondents with regards to their integration of IOK into practice. These shortcomings may affect the integration and implementation of IOK either in classrooms, clinics or offices and lead to a poor integration of the Islamisation agenda to the students as well as the patients. Hence, there is a need to design workshops and programmes more towards practical approaches of IOK into health-based sciences as well as the implementation of IOK agenda at the workplace, rather than the theoretical aspects per se. In conclusion, most of the respondents have positive attitude towards the IOK movement in KAHS despite the high level of knowledge among some members, in particular the academic staff, is not yet translated into practice.

Keywords: Allied Health Sciences, attitude, Islamisation, knowledge, practice, university.

\section{INTRODUCTION}

Islamisation of knowledge (IOK) as envisioned by the International Islamic University Malaysia (IIUM) is an alternative paradigm of constructing and developing knowledge and education in accordance with the worldview, fundamental principles, ethical values and norms of Islam. It is a fulfilment of a long-felt need of the Muslim community for a model of Islamic university education that can serve as an alternative to the existing conventional education based on the Western and secular model. ${ }^{1}$ This model is based on the classical Islamic philosophy of knowledge and education which is grounded in the worldview of the Qur'an and the Sunnah of the Messenger of Allah (peace and blessings be upon him). Current studies on IOK in practice are limited to faculties from social sciences. ${ }^{2}$ IOK or sometimes

Intan Azura SHAHDAN

Biomedical Sciences Dept,

Kulliyyah of Allied Health Sciences,

International Islamic University Malaysia,

Kuantan Campus.

Email: intan_azura@iium.edu.my referred to as Islamisation of human knowledge is defined as "the impact or significance of the process of Islamisation on the concept and pursuit of knowledge". ${ }^{3}$ Al-Attas (1978) defined IOK as "the liberation of man first from magical, mythological, animistic, national-cultural tradition, and then from secular control over his reason and his language". ${ }^{4}$ IOK movement at the university or faculty therefore can be interpreted as a movement to overhaul the current educational and organisational system, by the liberation of secularism and an effort to unite not only the intellects but as well as the "souls" of every employee towards the Tawhidic concept and the worldview of Islam. Much of the energy surrounding the student experience and student learning was placed on the staff members of faculty, academics and non-academic staff.However, due to the different experience, levels of education or salary difference, a lack of connectedness and team working between these two staff groups is inevitable. ${ }^{5}$ While these two different groups may have the potential to provide a rich environment for an academic organisation, it is easy to see the 
potential for conflict if eccentric behaviours, hidden agendas, and individual suspicions are thrown into the mix. ${ }^{5}$ Integrating spirituality in workplace is believed to give some impact on the effectiveness and success in organisations. ${ }^{6}$ It aims for more meaningful work, sense of belongings and value of the organisations. ${ }^{7}$ Most importantly, when there is lack of spirituality in the workplace, staff may lose spiritual and connectedness to The Creator and deviate from the ultimate purpose of work. Thus, the IOK movement is the key piece of puzzle that should overcome the differing views among faculty staff.

The International Islamic University Malaysia (IIUM), an institute which is founded by the Islamic principles and values, has a mission to integrate and Islamise all branches of knowledge and intellectual discourse so that they are in line with the Qur'an and the Sunnah. However despite her 33 years of numerous efforts for the IOK, there is much less delivery and implementation of IOK at the university level; and the little efforts were concentrated more on the social sciences. ${ }^{2}$ More often, IOK has been narrowed to mere implementation of the Shari'ah teachings. ${ }^{3}$ Another reason was perhaps that the issues on the modern philosophy in science courses were not seen as severe as compared to the social science courses. However with the advancement of technology, more ethical issues are raised concerning the application of scientific knowledge. This also applies to the medical and allied health sciences. Thus, it is timely that philosophy, science and religion - the three fundamental modes of thinking - are put together and being taught, discussed and debated at university level. This study aims to assess the knowledge, attitude and practice (KAP) of IOK in one of the health sciences faculties of IIUM, the Kulliyyah (Faculty) of Allied Health Sciences (KAHS).

KAHS is the sixth faculty in Malaysia which offers degrees in Allied Health Sciences. Like other Allied Health Sciences faculties, KAHS plays the tripartite roles of teaching, training clinicians and performing research. The uniqueness of KAHS lies on the realisation and implementation of the ideal vision and mission of the IIUM; that is to be the leading centre in the provision of knowledge and service in the field of health sciences towards achieving and reviving Islamic glory in Science and Technology. To achieve this, several programs are held every year to instil the IOK notion among faculty members.

Duration of service rationally influences the KAP. Longer duration of service ideally enhances knowledge on mission and vision of the respective institutions. It is believed that high level of knowledge will translate to positive attitude and practice. $^{8,9}$ However, these are not necessarily true. There were also findings showing no difference between KAP with duration of employment. ${ }^{10,11}$

Only a few studies were done to assess the success of IOK within IIUM. This study therefore aims to give a general overview on the current status in KAP of
IOK in KAHS. The specific objectives of the study include to investigate the: (i) perceptions of KAP among members of KAHS, IIUM regarding IOK; (ii) correlation of KAP with the duration of service and level of exposure to IOK-related activities; (iii) comparison of KAP between departments in KAHS; and (iv) comparison of KAP between KAHS academics and non-academics in understanding IOK.

\section{METHOD}

\section{Study design, area and population}

A cross-sectional study design was used to evaluate the KAP on IOK among the KAHS academics and nonacademic staff. The study was conducted in all six departments of the KAHS, IIUM. The departments were Biomedical Sciences (BMS), Nutrition Sciences (DNS), Physical Rehabilitation Sciences (PRS), Diagnostic Imaging and Radiotherapy (DIR), Optometry and Visual Sciences (OVS), and Audiology and Speech-Language Pathology (ASP).

Academics include lecturers who teach and train students in classrooms, laboratories and clinics, and also have the responsibility to plan and design course curricula. Non-academics include clinicians and managerial staff who are involved in running clinics and departments, and who sometimes involve in the training of students in clinics. Non-academic staff however have no involvement in planning and designing course curricula. The total active number of staff at KAHS is listed as the total number of prospective respondent in Table 1

Table 1. Number of respondents in the study

\begin{tabular}{lll}
\hline Staff group & $\begin{array}{l}\text { No. of sample } \\
\text { Number of } \\
\text { prospective } \\
\text { respondent }\end{array}$ & $\begin{array}{l}\text { Obtained } \\
\text { respondent }\end{array}$ \\
\hline Academics & 69 & 41 \\
Non-academics & 44 & 33 \\
Total & $\mathbf{1 1 3}$ & $\mathbf{7 4}$ \\
\hline
\end{tabular}

\section{Sampling method}

Respondents for this research were selected via convenience sampling. The respondents, irrespective of gender, were recruited based on their accessibility by the researchers. The sampling method was chosen because it would allow for the representation of the KAHS staff population.

\section{Research tool and data collection}

The collection of data was conducted in April 2015. The instrument used to collect data was a selfadministered questionnaire. The questionnaire was distributed to all active staff in KAHS, and the response rate was $65.5 \%$. The questionnaire consists of 17 items with a set of close-ended (rated as "Yes"- 2 marks, "No"-0 mark, or "Maybe"-1 mark) and open-ended questions, assessing the demographic, knowledge (K), attitude (A) and practice $(P)$ information. Fourteen items were commonly administered on academics and nonacademics, and additional 3 items (on practice assessment) were being administered for academic staff only (Table 2). When performing statistical analysis, parametric test was used when the 
normality assumption was met and non-parametric test was used whenever the normality assumption was not met.

Table 2. List of category and respective items in the questionnaire

\begin{tabular}{|c|c|}
\hline Category & Item* \\
\hline $\begin{array}{l}\text { Socio- } \\
\text { demographic }\end{array}$ & $\begin{array}{l}\text { Job position (academic and } \\
\text { non-academic), duration of ser- } \\
\text { vice, and the level of exposure of } \\
\text { IOK (number of attendance to IOK } \\
\text { related programmes). }\end{array}$ \\
\hline Knowledge & $\begin{array}{l}\text { Assessments on understanding of } \\
\text { IOK concepts, and the perception } \\
\text { on their understanding of several } \\
\text { important concepts of IOK (e.g. }\end{array}$ \\
\hline & $\begin{array}{l}\text { naturalism, secularism and ag- } \\
\text { nosticism). }\end{array}$ \\
\hline Attitude & $\begin{array}{l}\text { Participation and interest in cur- } \\
\text { rent and future IOK activities. }\end{array}$ \\
\hline Practice & $\begin{array}{l}\text { A general question on the integra- } \\
\text { tion of IOK in job scope was asked } \\
\text { for both academic and non- } \\
\text { academic staff. Additional ques- } \\
\text { tions for academic staff include on } \\
\text { whether they integrate and imple- } \\
\text { ment the IOK in their course out- } \\
\text { lines, lectures and assessments, } \\
\text { and if they do, the information on } \\
\text { the teaching method they used to } \\
\text { deliver the lOK. }\end{array}$ \\
\hline
\end{tabular}

The validity and reliability assessments of the questionnaire were performed prior to actual data collection. Content validation involved experts who are familiar with IOK concepts, mainly reviewed the validity of the items in measuring the KAP of IOK. Face validity involved administrative staff (nonrespondents) reviewing on the readability and the ease to understand the language used. Reliability analyses using Cronbach's alpha was conducted to determine the internal consistency of each item. A total of 10 items were analysed, excluding non-scale questions (open ended question), and demographic questions. The overall Cronbach's alpha (a) value was 0.77 which is an acceptable value $(\alpha>0.7)$ for the questionnaire to be considered reliable. ${ }^{12}$ Thus, none of the items was removed from the questionnaire.

\section{RESULT \& DATA ANALYSIS \\ General analysis}

Sixty-six percent of KAHS staffs responded in this study. The question assessing the demographic information (e.g. level of exposure), the knowledge and the attitude were kept the same between academic and non-academic staff, thus the overall mean of the knowledge, attitude, and level of exposure score is the average score from both academic and non-academic staff. On the other hand, the question assessing the practice aspect was different in academics and non-academic staff due to different nature of job practice between those two (Table 2). Thus, the practice score between these two groups were analysed separately.

Effects of job duration on level of exposure, knowledge and attitude, and practice
In order to understand whether or not there is an effect of job duration towards understanding and practising the IOK, the level of exposure and KAP scores were compared between different job duration categories. Figure 1 shows a) mean of level of exposure, b) mean of knowledge score, c) mean of attitude score, d) mean of practice scores for academics and non-academic staff; across different job duration categories. Mean comparison analysis revealed that level of exposure towards IOK and knowledge score increased with increasing job duration and the score increment was statistically significant $(p<0.05$; Figure $1 a$ and $1 b)$. Attitude score on the other hand did not increase with increasing job duration ( $p>0.05$ ). For practice score, no significant difference of practice score observed between different job duration among academics. While for non-academic staffs, the significantly higher practice score was recorded among those who have worked for 2 to 4 years, as compared to those who have just started working within a year ago, and those who have worked for 5 to 9 years.
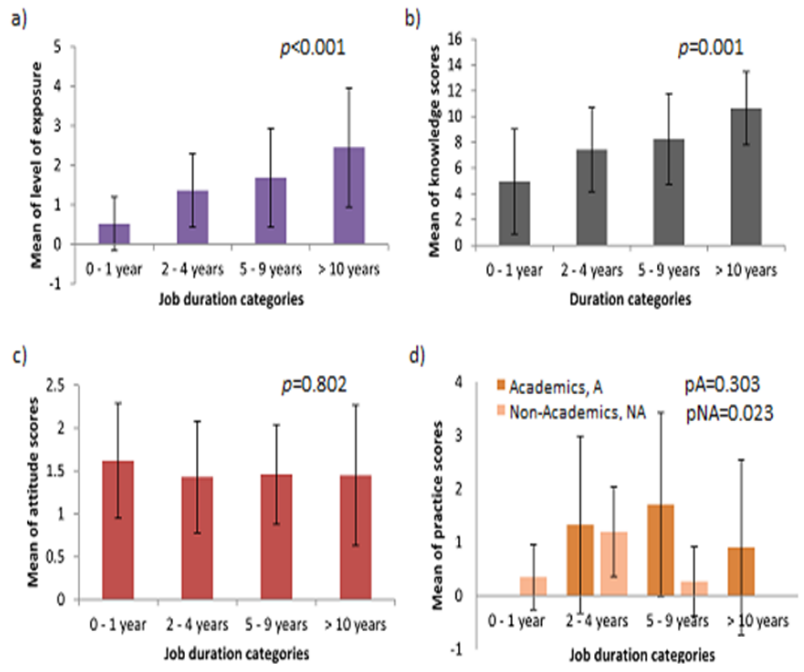

Figure 1. Effects of job duration on: a) Level of exposure, b) Knowledge score, c) Attitude score, and d) Practice scores for academics and non-academic staff. Bars show mean for each score. Error bars show standard deviation. P-value for mean comparison analysis is shown on the upper right corner of each graph.

\section{Factors associated with the knowledge} performance on IOK

To understand what are the factors associated with performance of knowledge or understanding of IOK, correlation analysis between knowledge score and other scores; level of exposure, attitude, practice; was performed (refer to Table 3 for analysis of result). The only significant positive correlation was observed between knowledge and level of exposure on IOK activities $(\mathrm{p}<0.05)$, but not with other variables such as attitude and practice $(p>0.05)$. This result indicates that knowledge increases with increasing level of exposure towards IOK (i.e. the frequency and the number of attending IOK related activities). However, attitude and practice on the other hand did not correlate with knowledge performance. 
Table 3. Correlation analysis between different variables

\begin{tabular}{|c|c|c|c|c|c|}
\hline Variable $_{1}$ & Variable 2 & Job position & Sample size, $n$ & $\begin{array}{l}\text { Correlation } \\
\text { coefficient, } \\
r\end{array}$ & p-value \\
\hline Knowledge & Level of exposure & General $^{a}$ & 74 & 0.37 & $0.001^{* *}$ \\
\hline Knowledge & Attitude & General $^{a}$ & 74 & 0.15 & 0.21 \\
\hline \multirow{2}{*}{ Knowledge } & \multirow{2}{*}{ Practice } & Academics & 41 & 0.28 & 0.07 \\
\hline & & Non-academics & 33 & 0.33 & 0.06 \\
\hline \multirow{2}{*}{ Practice } & \multirow{2}{*}{ Attitude } & Academics & 41 & 0.08 & 0.61 \\
\hline & & Non-academics & 33 & 0.17 & 0.35 \\
\hline
\end{tabular}

\section{KAP scores according to departments}

To investigate the performance of every department in KAHS on IOK practice and understanding, the KAP scores were compared between departments. For practice analysis of administrative staff, DIR department was excluded from analysis as only one staff participated in the survey. All other departments performed similarly in terms of knowledge and attitude performance; no significant difference was observed on knowledge and attitude score between departments ( $>0.05$; Figure 2$)$. However, significant difference of practice among non-academic staff was observed between departments with ASP was recorded to have higher perception of practice level as compared to other departments, followed by BMS, OVS, PRS and DNS. Maximum practice scores for non-academic staff is 2 whilst for academic staff is 5 (Figure 1d).

a)

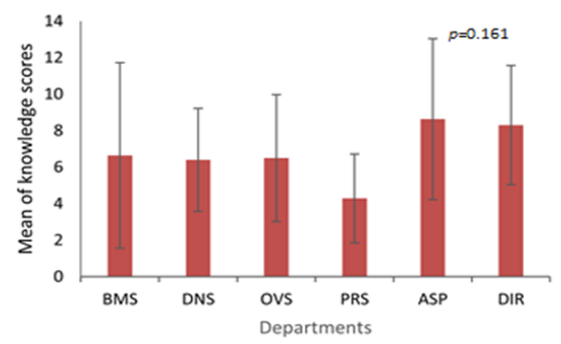

b)

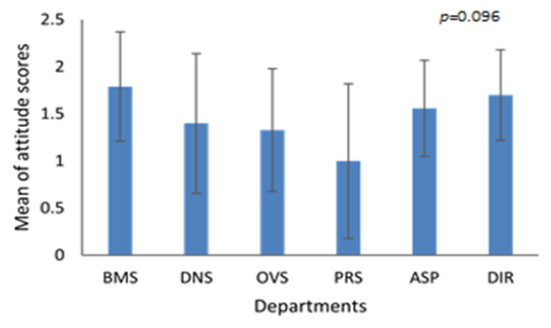

c)

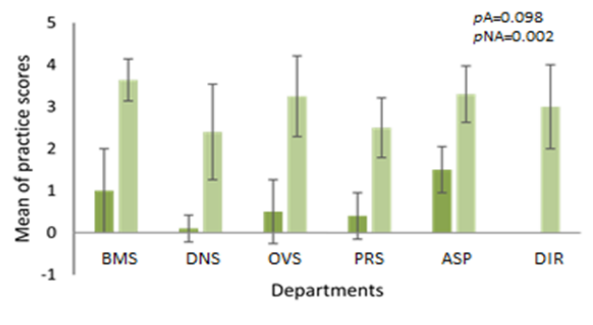

Figure 2. Analysis of the performance of knowledge, attitude and practice scores between departments in Kulliyyah of Allied Health Sciences, International Islamic University Malaysia: a) Knowledge score, b) Attitude score, c) Practice scores for academic and administrative staff. Bars show means for each score. Error bars show standard deviation. P-value for mean comparison analysis is shown on the upper right corner of each graph. BMS, Biomedical Science Department, DNS, Department of Nutritional Science, OVS, Optometry and Visual Sciences, PRS, Physical Rehabilitation Sciences, ASP, Audiology and Speech-Language Pathology, DIR, Diagnostic Imaging and Radiotherapy.

Knowledge and attitude according to job position Comparison of knowledge and attitude score between academics and non-academic staff was performed (Figure 3). Academics showed significantly higher knowledge and attitude score than non-academic staff $(p \leq 0.05)$.
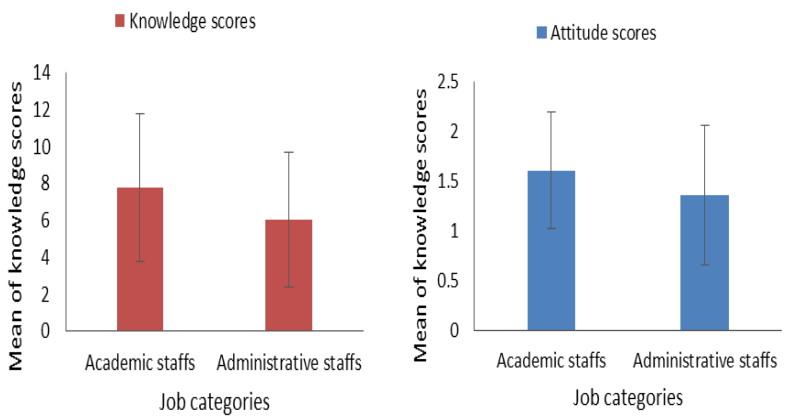

Figure 3. Knowledge and attitude scores between job positions: a) Knowledge score and b) Attitude score, for both academics and non-academic staff. Bars show means for each score. Error bars show standard deviation. P-value for mean comparison analysis is shown on the upper right corner of each graph.

\section{Discussion}

The success of Islamisation agenda in any university is a collective work and effort within and between faculties, as well as the understanding on the IOK programme among academics and non-academics alike. Currently the study of Islamisation within the science-based faculty is lacking. Our preliminary study which evaluated KAP towards IOK movement among faculty members of KAHS, IIUM, is an effort to 
design questionnaire and gather information that can be utilised to assess the effectiveness of the current activities on IOK in a science-based faculty.

Level of exposure and knowledge positively correlated with job duration

The longer the period of working, the higher the knowledge on IOK is for the KAHS staff members (Figure 1). This is consistent with the participation of staff in various IOK program organised by various offices in IIUM throughout the year. When asked about their ability on explaining IOK, majority of respondents could answer in affirmative. IIUM and Kuantan Campus in particular organised numerous IOK related activities for staff such as the yearly Ibadah Camp, as well as other programmes that involve both staff and students such as Workshop on Integration of Knowledge (I-WIN). Ibadah camp is a compulsory annual event, attended by all administrative and academic staff of IIUM. Its modules are developed by the Centre for IslamisationorCENTRIShttp://www.iium.edu.my/ce ntris), and mainly focused on the development of Islamic values among the staff. I-WIN is also another activity organised by the CENTRIS which aims to discuss the current issues in health, science and environment by giving the Islamic perspective in these issues. The programme and encouraging atmosphere on the campus thus indeed help in promoting the understanding of the IOK concept.

However, no correlation was found between attitude and practice scores with increasing level of exposure and job duration (Figure 1). The finding is also consistent with previous KAP-related studies. ${ }^{10,11}$ This may suggest that, even though the staff are long in service with IIUM and has an understanding on IOK idea; it did not affect their perception towards IOK.

\section{Good knowledge is not translated into practice}

Subsequently, despite the knowledge on Islamisation gained by these staff, this was not translated into practice, in particular for the academic group. One of the explanations would be that IOK is relatively "new" to pose an impact towards the staff. Only in these recent years that IOK begins to attract the interest of more junior academics as well as the non-academic groups as compared to the earlier years when IOK was first introduced. From general observation of the authors, a possible reason might be due to absence of enforcement and evaluation for practice of IOK. Academics may not see the importance of implementing IOK in their academic practice.

There were also opinions among the academics that there are no conflicting or contradicting issues or theories of the existing syllabus with Islamic knowledge. Hence, when asked on how IOK can be improved, they answered 'no changes' are needed, leading to the average practice score (Figure 2c). While for the non-academic groups, the higher practice score on IOK may be a positive indication of IOK influence in their daily work. However, the authors admit that the result of practice domain might be biased based on the construction of the questionnaires in this pilot study. Hence, from the preliminary work of this study, the authors have identified several ways to improve the assessment of KAP towards IOK, which include: i) development of a standardised scaled questions for improvements on standardised scoring system; ii) addition of subitems under each domain to assess the KAP information better; and iii) involvement of larger number of respondents to better represent the faculty's perspective.

\section{CONCLUSION}

Most of the respondents are keen to implement IOK movement in KAHS. However, both academics and non-academic staff should be helped to understand the concept of IOK. Lectures, trainings and workshops on IOK related matters should now be focusing on the practical solutions, such as on how to write textbooks in Islamisation of health sciences, or how to review and criticise modern and western theories in medical and health sciences, to include the Tawhidic concept and Islamic values. ${ }^{13}$ At clinical level, more can be done to imbue Islamic doctor-patient relationship and to instil the concept of health, sickness and sense of reliance towards Allah, the One who Cures. At administrative level, the integrity, Syura concept and other Islamic values should be put into practice. Adopting International Organisation for Standardisation (ISO) or other accreditation system for offices, to be in line with the IOK movement, is also one way to instil work as Ibadah concept among staff, so that every worker has the sense of accountability towards his Creator, and will perform his best in all tasks given. This way, all efforts in IOK can focus on both knowledge as well as the people who are practicing it.

\section{ACKNOWLEDGMENT}

Authors thank the Dean of KAHS, Dr. Wan Azdie Mohd Abu Bakar for his moral support on this project. Committee members of faculty's IOK 2015 are thanked for their involvement in distributing and compiling the questionnaires from various departments. This study was funded by Research Initiative Grant Scheme (Grant no: RIGS 16-1250289).

\section{REFERENCES}

1. Centre for Islamisation (CENTRIS). IIUM policies and guidelines on Islamisation. CENTRIS: Kuala Lumpur 2013:22-25.

2. Hashim R. Internationalisation of Contemporary Islamic Higher Education and Ummatic Development: A Case Study of the International Islamic University Malaysia (IIUM).Paper presented at the International Seminar on Reforms in Islamic Higher Education in Meeting Contemporary Challenges, Nagoya University 
30-31 July, 2011.

3. Nasr SVR. Islamization of knowledge: a critical overview. Islamic Studies 1991;30(3):387-400

4. Al-Attas SMN. The Dewesternization of Knowledge. In: Islam and Secularism. Kuala Lumpur: Muslim Youth Movement of Malaysia (ABIM), 1978:133-150.

5. Berryman-Fink C. Can We Agree to Disagree? Faculty-Faculty Conflict. In Holton, S.A. (Ed.), Mending the Cracks in the Ivory Tower: Strategies for Conflict Management in Higher Education, Bolton, MA: Anker Publishing Company, Inc., 1998:141-163.

6. Dehaghi MR, Goodarzi M and Arazi ZK. The Effect of Spiritual Values on Employees' Organizational Commitment and Its Models. Procedia - Social and Behavioral Sciences 2012;62:159-166.

7. Hassan M, Bin Nadeem A, Akhter A and Nisar T. Impact of workplace spirituality on job satisfaction: Mediating effect of trust. Cogent Business \& Management 2016;3(1):1189808. http://dx.doi.org/10.1080/23311975.2016.118 9808. Accessed 22 May, 2017.

8. Svanström R, Andersson S, Rosén $H$, Berglund M. Moving from theory to_practice: experience of implementing a learning supporting model designed to increase patient involvement and autonomy in care. BMC Res Notes 2016;9:361.

9. Zuba EB, Francuzik W, Malicki P, OsmolaMańkowska A, Jenerowicz D. Knowledge_about Ultraviolet Radiation Hazards and Tanning Behavior of Cosmetology and Medical Students. Acta Dermatovenerol Croat 2016;24(1):73-7.

10. Osinowo HO. Influence of Duration and Pattern of Work on Knowledge of AIDS/STDs and Practice of Safer Sex Methods among Commercial Sex Workers and Control Group as Non-Commercial Sex Workers in Ibadan Metropolis. Nigerian Journal of Clinical and Counselling Psychology 2001;7(1):43-54.

11. Mohd Rahim S, Aziah BD, Mohd Hazri S, Azwany NY, Habsah H, Zahiruddin WM, Zaliha I, Mohamed Rusli A. Town service workers' knowledge, attitude and practice towards leptospirosis. Brunei Darussalam Journal of Health 2012;5:1-12.

12. Bland JM, Altman DG. Statistics notes: Cronbach's alpha. BMJ, 1997;314:572.

13. Abdallah SS, Hussien S, Hisham NA. The experience of Islamization of Knowledge at the International Islamic University Malaysia: successes and challenges. In: New Intellectual Horizons in Education. IIUM Press, Gombak, 2011:91-110. 